Case report

\title{
Bloody tears and hematohidrosis in a patient of PF3 dysfunction: a case report Kusum L Mishra
}

Address: Department of Pathology, Laboratory of Coagulation Disorder, C S M Medical University, Lucknow, Uttar Pradesh, 226003 , India Email: kusum_niwas@rediffmail.com

Received: 2 March 2009 Accepted: 17 August 2009 Published: 15 September 2009

Cases Journal 2009, 2:9029 doi: 10.4076/1757-1626-2-9029

This article is available from: http://casesjournal.com/casesjournal/article/view/9029

(C) 2009 Mishra; licensee Cases Network Ltd.

This is an Open Access article distributed under the terms of the Creative Commons Attribution License (http://creativecommons.org/licenses/by/3.0), which permits unrestricted use, distribution, and reproduction in any medium, provided the original work is properly cited.

\begin{abstract}
Introduction: Abnormal bleeding may result from deficiency of one of the clotting factors.

Case presentation: A 13-year-old Indian girl, presented with a history of bleeding following minor injury, epistaxis, and hematuria, bleeding from gums, subcutaneous bleeding and gastro intestinal tract bleeding. She underwent a complete coagulation profile test, CT scan and ultrasound. Platelet Factor 3 dysfunction was diagnosed to be the cause of bleeding. Patient was transfused fresh frozen plasma and platelet as part of treatment. Condition of the patient after four months of diagnosis deteriorated and she started bleeding in tears and sweat.
\end{abstract}

Conclusion: A thorough examination and proper workup are necessary to determine the exact cause and rule out serious conditions.

\section{Introduction}

Depletion of any of the clotting factor leads to bleeding from different sites. Platelet factor 3 availability (PF3-A) being an insensitive to plasma coagulation factors are highly specific and reproducible [1]. Clotting time of intact platelet rich plasma decreases due to the activation of Hageman and plasma thromboplastin antecedent (PTA) and from release of platelet factor 3 (PF3) in the presence of kaolin. Subconjuctival hemorrhage leading to bloody tears is common in acute Epstein Barr virus [2] in nonaccidental trauma [3], factor XIII Val34Leu polymorphism [4] and idiopathic thrombocytopenic purpura [5]. Reports from different research on PF3 availability [6] (platelet coagulant activity) revealed variety of congenital and acquired disorder [7] but no report of bloody tears and bleeding sweat (Hematohidrosis) in patients with PF3 defect received yet. In the present case, medical history and clinical examination of the patient for any other pathology were negative. The appearance of spontaneous subconjunctival hemorrhage and hematohidrosis in a patient of PF3 release defect needs thorough investigation, as it can be an indication of some threatening disorder. PF3 test performed by mixing platelet rich control plasma with platelet poor test plasma and comparing the clotting time with the mixture of platelet rich test plasma and platelet poor control plasma in the absence of phospholipid. The difference between the two clotting time for more than 3 secs revealed defect in platelet factor 3 release.

\section{Case presentation}

A 13-year-old school-going Indian girl child complained of bleeding from gums, hematuria, sub cutaneous 
Table I. Table shows patients complete coagulation profile

\begin{tabular}{lll}
\hline Investigations & Control (secs) & Test (secs) \\
\hline Prothrombin Time (PT) & 14 & 14 \\
Activated Partial Thromboplastin & 24 & 24 \\
Time (APTT) & & \\
Thrombin Time (TT) & II & II \\
Bleeding Time (BT) & $2-7$ minutes & 2 mins 45 secs \\
Platelet Function (PF 3) & 30 & 41 \\
\hline
\end{tabular}

bleeding, gastrointestinal bleeding which she regurgitates and collects in her oral cavity, prolonged bleeding after minor trauma and history of epistaxis. Patient later developed conjunctival hemorrhage leading to bloody tears and hematohidrosis. There was no family history of bleeding. The complete coagulation profile [8] is normal except PF 3 (Table 1). Platelet count is normal (1.95 lacs $/ \mathrm{cmm})$.

\section{Discussion}

Subconjunctival hemorrhage and hematohidrosis observed as the secondary presenting clinical feature of PF3 dysfunction for the first time in the present study. Sodhi and Jose [5] earlier reported subconjunctival hemorrhage for the first time in a case of idiopathic thrombocytopenic purpura. The glycoprotein Ia/Ila of platelet membrane plays a major role in platelet function as a primary receptor for collagen [9]. Chief Medical Examiner of Rockland Country, New York [10] has explained that around the sweat glands, there are multiple blood vessels in a net-like form. Under the pressure of great stress, the vessels constrict. Then as the anxiety passes, "the blood vessels dilate to the point of rupture and the blood goes into the sweat glands." As the sweat glands are producing a lot of sweat, it pushes the blood to the surface coming out as droplets of blood mixed with sweat. It is still not clear how PF3 dysfunction relates with bloody tears and hematohidrosis. Further research in this direction is required to unearth the reason for unusual bleeding.

\section{Conclusion}

A case of PF3 dysfunction shows an unusual clinical secondary entity of hematohidrosis and bloody tears for the first time. It can be very complicating for the clinician. A thorough examination and proper workup are necessary to determine the exact cause and rule out serious conditions.

\section{Consent}

Parents of the patient gave the written informed for publication of this case report. A copy of the written consent is available for review by the Editor-in-Chief of this journal.

\section{Competing interests}

The author declares that there are no competing interests with any author.

\section{Authors' contributions}

KLM was solely responsible for conducting, writing and editing this manuscript.

\section{Acknowledgement}

I thank Prof. M R S Kushwaha, Head of the Pathology Department, C S M Medical University, Gandhi Memorial and Associated Hospital for granting the permission to conduct work and giving the laboratory facility during the course of this study.

\section{References}

I. Frederick SR, Otto H: Platelet Factor 3 in normal subjects and patients with renal failure. The J of Clinical Investigation 1968, 47:901-912.

2. Kanafani ZA, Bashur Z, Kani SS: Acute epstein-barr virus infection causing bilateral conjunctival hemorrhages. South Med J 2005, 98:390-39l.

3. Spitzer SG, Luorno J, Noel LP: Isolated subconjunctival hemorrhages in nonaccidental trauma. J AAPOS 2005, 9:53-56.

4. Parmeggiani F, Costagliola C, Incorvaia C: Prevalence of factor XIII Val34Leu polymorphism in patients affected by spontaneous subconjunctival hemorrhage. Am J Ophthalmol 2004, I38:48I484.

5. Sodhi PK, Jose R: Subconjunctival hemorrhage:the first presenting clinical feature of idiopathic thrombocytopenic purpura. Jpn J Ophthalmol 2003, 47:316-318.

6. Hardisty RM, Hutton RA: The kaolin clotting time of plateletrich plasma: A test of platelet factor-3 availability. Brit J Haematol 1965, I I:258-262.

7. Castaldi PA, Larrieu MJ, Caen J: Availability of platelet factor 3 and activation of factor XII in thrombasthenia. Nature I965, 207:422-424.

8. Pitney WR, Brozovic M: From Laboratory control of anticoagulant and thrombolytic therapy. In Practical Hematology. $6^{\text {th }}$ edition. Edited by Dacie JV, Lewis SM. Edinburgh: Churchill Livingstone; 1984:259-266.

9. Moshfegh K, Wuillemin WA, Redondo M, Lammle B, Beer JH, LiechtiGallati S, Meyer BJ: Association of two silent polymorphisms of platelet glycoprotein Ia/lla receptor with risk of myocardial infarction: A case-control study. Lancet 1999, 353:35I-354.

10. Frederick Z: Sweating Blood. Annacheriyan-ga 2006, 34: I4-I6.

\section{Do you have a case to share?}

\author{
Submit your case report today \\ - Rapid peer review \\ - Fast publication \\ - PubMed indexing \\ - Inclusion in Cases Database
}

\section{Any patient, any case, can teach us something}

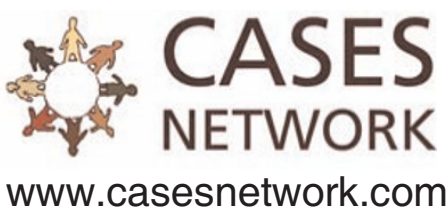

